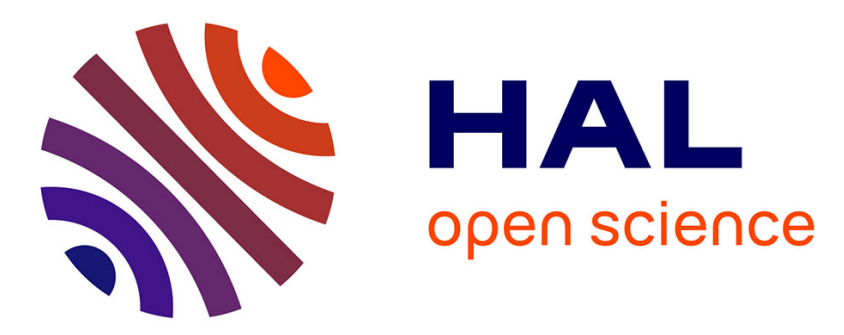

\title{
Birthweight difference of singletons conceived through in vitro fertilization with frozen versus fresh embryo transfer: An analysis of 5406 embryo transfers in a retrospective study $2013-2018$
}

\author{
Maude Laval, Ronan Garlantezec, Anne Guivarc'H-Levêque
}

\section{To cite this version:}

Maude Laval, Ronan Garlantezec, Anne Guivarc'H-Levêque. Birthweight difference of singletons conceived through in vitro fertilization with frozen versus fresh embryo transfer: An analysis of 5406 embryo transfers in a retrospective study 2013-2018. Journal of Gynecology Obstetrics and Human Reproduction, 2020, 49 (1), pp.101644. 10.1016/j.jogoh.2019.101644 . hal-02364723

HAL Id: hal-02364723

https://hal-univ-rennes1.archives-ouvertes.fr/hal-02364723

Submitted on 9 Dec 2019

HAL is a multi-disciplinary open access archive for the deposit and dissemination of scientific research documents, whether they are published or not. The documents may come from teaching and research institutions in France or abroad, or from public or private research centers.
L'archive ouverte pluridisciplinaire HAL, est destinée au dépôt et à la diffusion de documents scientifiques de niveau recherche, publiés ou non, émanant des établissements d'enseignement et de recherche français ou étrangers, des laboratoires publics ou privés. 


\title{
Birthweight difference of singletons conceived through in vitro fertilization with frozen versus fresh embryo transfer: An analysis of 5406 embryo transfers in a retrospective study $2013-2018$
}

\author{
Maude Laval, Ronan Garlantezec, Anne Guivarc'H-Levêque
}

\section{To cite this version:}

Maude Laval, Ronan Garlantezec, Anne Guivarc'H-Levêque. Birthweight difference of singletons conceived through in vitro fertilization with frozen versus fresh embryo transfer: An analysis of 5406 embryo transfers in a retrospective study 2013-2018. Journal of Gynecology Obstetrics and Human Reproduction, Elsevier, In press, 10.1016/j.jogoh.2019.101644 . hal-02364723

HAL Id: hal-02364723

https://hal-univ-rennes1.archives-ouvertes.fr/hal-02364723

Submitted on 9 Dec 2019

HAL is a multi-disciplinary open access archive for the deposit and dissemination of scientific research documents, whether they are published or not. The documents may come from teaching and research institutions in France or abroad, or from public or private research centers.
L'archive ouverte pluridisciplinaire HAL, est destinée au dépôt et à la diffusion de documents scientifiques de niveau recherche, publiés ou non, émanant des établissements d'enseignement et de recherche français ou étrangers, des laboratoires publics ou privés. 
Birthweight difference of singletons conceived through in vitro fertilization with frozen versus fresh embryo transfer : an analysis of 5604 embryo transfers in a retrospective study 2013-2018

Laval M, Garlantézec R, Guivarc'h-Levêque A

Laval Maude, Gynecologist, Reproductive Medicine, Groupe Hospitalier Bretagne Sud, 5 avenue Choiseul, 56322 Lorient, France, maude.laval@gmail.com

Garlantézec Ronan, University of Rennes, Inserm, EHESP, Irset (Institut de recherche en santé, environnement et travail) 9 Avenue du Professeur Léon Bernard, 35000 Rennes ; Centre Hospitalier Universitaire de Rennes, 2 Rue Henri le Guilloux, 35000 Rennes, France, ronan.garlantezec@chu-rennes.fr

Guivarc'h-Levêque Anne, Gynecologist, Reproductive Medicine, Clinique de La Sagesse, 4 Place Saint Guénolé 35043 Rennes, France, anne.guivarch@orange.fr

Clinique de La Sagesse, 4 place Saint Guénolé 35043 RENNES

https://www.evise.com/evise/faces/pages/submission/Submission.jspx?_adf.ctrlstate=v6k9bmjs9_29

https://www.elsevier.com/journals/journal-of-gynecology-obstetrics-and-humanreproduction/2468-7847/guide-for-authors

\section{Abstract}

Introduction. Perinatal risks after frozen embro transfer (FET) have been reassuring but some authors suggest that birthweights are higher after FET than after fresh embryo transfer (ET). The primary objective of this retrospective study, conducted in Clinique de la Sagesse, Rennes (France) from December 2013 to March 2017, was to determine whether a difference in birthweight exists between children conceived through in vitro fertilization (IVF) with frozen versus fresh ET. The secondary objective was to compare live birth rates after frozen versus fresh cycles.

Material and methods. All couples undergoing IVF were included. Cycles with gamete donation and twin pregnancies were excluded. Hormone therapy was used in all embryo transfers. The main outcome measures were the child's birthweight, mode of delivery, gestation length and sex, maternal characteristics, and IVF characteristics. The primary endpoint was birthweight.

Results. We studied 5406 embryo transfers and the 708 resulting singleton live births on which birthweight data were available. Mean birthweight was $3357 \mathrm{~g}$ after frozen embryo transfer versus $3183 \mathrm{~g}$ after fresh embryo transfer $(p<0.001)$. After adjusting for confounding factors, the children born after frozen embryo transfer were $165.2 \mathrm{~g}$ heavier (95\% CI [92.96-237.51]). No difference was found in gestation length. Live birth was obtained after the $1.6^{\text {th }}$ IVF attempt. Live birth rate was higher for fresh cycles ( $19 \%$ versus $12 \%, p<0.001)$, and the caesarean rate lower (16\% versus $21 \%$ ). 
Year: 2018

Discussion. Birthweight was higher after frozen embryo transfer for a similar gestational age. Further research is needed to elucidate the mechanisms responsible for this difference.

\author{
Keywords: in vitro fertilization; frozen embryo transfer; fresh embryo transfert; birthweight; live \\ birth;
}

\title{
Introduction
}

Since the birth of the first child conceived through in vitro fertilization (IVF) in 1978, considerable advances have been made in the treatment of infertility, and the number of children born through these techniques increases every year. Concerns about the health of these children have prompted various groups to study the perinatal risks of pregnancies conceived through assisted reproductive technology (ART). Although outcomes are comparable with those observed after natural conception, ART appears to be associated with more obstetrical and neonatal complications (1-3). This difference is thought to be due to underlying parental factors rather than the ART procedures (4-6).

The reduction in the number of embryos transferred per attempt has reduced the incidence of multiple pregnancy and perinatal morbidity (7-9), a strategy made possible by the freezing of excess embryos and their use in subsequent transfers $(3,10)$. This approach increases the cumulative chances of pregnancy per IVF cycle (11), offering the possibility, when fresh embryo transfer (ET) fails, of carrying out a second transfer without repeating the stimulation-aspiration step if excess embryos were frozen.

Progress in embryo cryopreservation, and especially in vitrification, has led to improved embryo survival since 2010 (6). Publications have shown vitrification to be safe and superior to slow freezing (12), and pregnancy rates obtained after the transfer of thawed vitrified embryos have been similar to those achieved with fresh ET in some studies $(3,13)$. FET is a straightforward procedure, in which the only preparation required is to ensure endometrial receptivity to embryo implantation (6).

Cryopreservation techniques allowed the implementation of the "freeze-all" strategy: the entire cohort of embryos is cryopreserved to be transferred to the uterus in subsequent cycles in a more physiological environment, avoiding the supra-physiologic hormonal levels observed during controlled ovarian stimulation (COS). Freeze all strategy also usefull to avoid OHSS (Ovarian Hyper Stimulation..), for genetic testing, and when premature progesterone elevation or others endometrial abnormalities discovered over the course of controlled ovarian stimulation. The number of frozen embryo transfers (FETs) and children born through FET have thus increased in recent years $(9,10,12)$, and in 2016 , FET was used in $25.7 \%$ of births in France achieved through ART (13).

Comparisons of the perinatal risks associated with pregnancies obtained through FET versus fresh ET have been reassuring $(1-3,12,14-16)$. Despite concerns that IVF would result in babies with low birthweights for their gestational age (risk of low birth rate OR 1.48, $95 \% \mathrm{Cl}: 1.37,1.60)(6)$, only fresh ET increases the risk of low birthweight (LBW <2500g) among singletons $(5,6)$, and various studies suggest that birthweights are higher after FET than after fresh : Wennerholm and al. have found OR 0.81 (CI 0.71-0.91) of LBW after FET versus fresh ETs $(14,16,17)$, but a French large study was missing on this important subject. 
Year: 2018

The aim of this study was to compare the birthweights of children conceived through IVF with fresh ET versus FET in a French infertility clinic and to compare the live birth rates obtained through these two approaches.

\section{Material and methods}

\section{Population, inclusion and exclusion criteria}

This retrospective study included all the couples who received IVF at Clinique de la Sagesse, Rennes, France between 01 December 2013 and 01 March 2017 provided the woman was aged 18 to 43 years.

Cycles were excluded if they involved donor gametes, natural cycle IVF, conversion to intrauterine insemination or ovulation induction alone, FET with ovulation stimulation, or if the patient was lost to follow-up. Twin pregnancies were excluded from the analysis of birthweights.

\section{$\underline{\text { Ovarian stimulation and IVF }}$}

All the women underwent ovarian stimulation with injections of recombinant gonadotrophins, or urinary gonadotrophins.

The starting dose of gonadotrophins (100-450 IU/day) depended on the patient's age, ovarian reserve, and body mass index (BMI). In repeat attempts, the dose was adjusted based on the previous cycle.

Various stimulation protocols were chosen depending on the patient, with either a gonadotrophinreleasing hormone (GnRH) antagonist (cetrorelix [Cetrotide, Merck] $0.25 \mathrm{mg}$, or ganirelix [Orgalutran, NV Organon] $0.25 \mathrm{mg}$ ) or a GnRH agonist (triptorelin [Décapeptyl, Ipsen] $0.1 \mathrm{mg}$ ).

Serum levels of 17beta-estradiol, luteinizing hormone and progesterone were monitored from the sixth day of stimulation. Transvaginal ultrasound was performed to count and measure average follicle size and to assess endometrial thickness and appearance. Gonadotrophin doses and the duration of stimulation were adjusted on the basis of this monitoring. Ovulation was induced by injecting $250 \mathrm{mg}$ of recombinant human chorionic gonadotrophin (hCG) (Ovitrelle, Merck) or the $\mathrm{GnRH}$ agonist triptorelin (Décapeptyl, Ipsen, 2 vials containing $0.1 \mathrm{mg}$ each), depending on ovarian response and protocol type.

Oocytes were retrieved 36 hours after ovulation induction, under general or local anaesthesia, depending on the patient's preference and local conditions. During this time, semen was collected in the laboratory. IVF or IVF-ICSI (intracytoplasmic sperm injection) was then performed. Vaginal progesterone was initiated for luteal phase support (Utrogestan, Besins; Estima, Effik; Progestan, Besins).

Fresh embryos were transferred 2 to 5 days after oocyte retrieval. The number of embryos transferred and their stage were selected on a case-by-case basis. Excess embryos were frozen by vitrification.

Vaginal progesterone was prescribed until the beta-hCG pregnancy test, 12 days after the procedure. The test was repeated twice, at 48 -hour intervals, to assess beta-hCG kinetics. Vaginal progesterone was continued for 1 month if the patient was pregnant. 
Year: 2018

\section{Vitrification protocol}

Vitrification is an ultrarapid cryopreservation technique in which liquids acquire a glass-like state (an amorphous solid in which the atoms remain disordered) with limited crystal formation.

Any embryos of sufficient developmental and morphological quality that were not transferred fresh were vitrified and stored for later use in case fresh ET failed to result in pregnancy. The vitrification method complied with France's Order on good medical laboratory practice (GBEA, dated 26 November 1999), national bioethics legislation, and international standards of quality and competence in medical laboratories (ISO 15189).

Vitrification medium (Kitazato, Cryotop ${ }^{\circledR}$ Method, Tokyo, Japan), containing ethylene glycol, dimethyl sulphoxide (DMSO), trehalose, and hydroxypropyl cellulose, was removed from the refrigerator 30 minutes before use. The embryo was dehydrated by placing it in a drop of equilibration medium at the centre of a Petri dish for 10 minutes, to allow water to be replaced by cryoprotectant. Next, the embryo was transferred into a drop of vitrification medium for 1 minute and 30 seconds, then into the gutter for insertion into a straw. The straw was labelled with patient information, sealed, then immersed in liquid nitrogen for ultrarapid cooling from $37^{\circ} \mathrm{C}$ to $-196^{\circ} \mathrm{C}$ to ensure high cell viability.

\section{Frozen embryo transfer}

After thawing, each embryo was inspected to assess the number of cells present. Embryos were considered to have successfully survived the thawing process, and thus eligible for FET, if more than $50 \%$ of the cells were intact. The number of embryos transferred and their stage depended on the couple.

Patients were prepared for FET with estradiol oral tablets (Provames $2 \mathrm{mg}$ ) until an endometrial thickness of at least $6 \mathrm{~mm}$ was attained. Vaginal estradiol was prescribed if endometrial development was insufficient. Natural progesterone was administered vaginally for as many days as necessary before ET, corresponding to its stage. Estradiol and progesterone were continued until the pregnancy test, and until 12 weeks of gestation if the patient was pregnant. If she was not pregnant, a new attempt was discussed. Pregnant patients were followed until the end of pregnancy.

\section{Data collection}

Medical and sociodemographic information were collected with MediFirst software (Medifirst-AMP, Montigny-le-Bretonneux, France), registered with the French data protection authority (CNIL) in accordance with national data protection and civil liberties law (No. 78-17 dated 6 January 1978).

The data collected were: the patient's age, weight, height, BMI, parity, duration and type of infertility (primary or secondary), ART type (IVF or IVF-ICSI), ART attempt number, stimulation protocol type (antagonist, long agonist or short agonist), smoking status, anti-Müllerian hormone (AMH) level, estradiol level at ovulation induction, progesterone level at ovulation induction and before FET, the number of oocytes obtained, the number and stage of embryos transferred, endometrial thickness before embryo transfer, number of estradiol tablets, type of ET (fresh or frozen), ET outcome (no pregnancy, pregnancy loss or live birth), number of liveborn infants, gestational age at birth, mode of delivery, and the child's sex and birthweight. Information was collected from January $1^{\text {st }} 2018$, i.e. 9 months after the last ET. 
Pregnancy outcome data were collected by our centre when the patient delivered there, or by contacting the patient directly after the expected delivery date.

Duration of infertility was defined as the time from when the couple started having regular unprotected intercourse without pregnancy to the time of inclusion in the study. Primary infertility was defined as absence of pregnancy in the current relationship (18).

Clinical pregnancy was defined as the detection by ultrasound of an embryo with cardiac activity 6 weeks after the patient's last menstrual period.

\section{Endpoints}

The primary endpoint in this comparison of FET versus fresh ET was birthweight. Furthermore, we studied the risk of macrosomia $(>4000 \mathrm{~g})$. The secondary endpoints were clinical pregnancy rate and live birth rate.

\section{$\underline{\text { Statistical analyses }}$}

Quantitative variables are expressed by their mean and standard deviation. Qualitative variables are expressed by the number and percentage of observations. Quantitative variables were compared with qualitative variables using student tests. Qualitative variables were compared using Fisher's exact test or the chi-square test, whichever was applicable.

The association between ET type (fresh versus frozen) and birthweight was explored using multiple linear regression, with birthweight as the dependent variable. Only singleton live births were included in this analysis $(n=762)$. The adjustment variables were chosen a priori, based on growth models (see Obstetrical, Perinatal and Paediatric Epidemiology research team, EPOPé) (19): mother's weight before the pregnancy, mother's height, height squared, parity, gestational age at birth, gestation squared, gestation cubed, and the baby's sex. The results on the association between birthweight and ET type are expressed with $95 \%$ confidence interval. In addition we performed a multiple linear regression to study the relation between ET type and Birthweight $Z$ score adjusted for the same set of covariates except gestational age variables.

The association between ET type and pregnancy outcome (live birth versus no pregnancy or pregnancy loss) was explored using logistic regression, with pregnancy outcome as the dependent variable. The adjustment strategy was to include variables in the initial model that were associated with a negative outcome in univariate analysis, with a $p$-value $<0.2$. Backward stepwise selection $(p=0.2)$ was then performed to construct the final model. The results are expressed as the odds ratio $(\mathrm{OR})$ and its $95 \%$ confidence interval; $p$-values $<0.05$ were considered statistically significant.

The CNGOF ethics committee approved this study (CEROG-2010-010).

\section{Results}

Between 01 December 2013 and 01 March 2017, 6721 ETs were performed at the Clinique de la Sagesse, Rennes, 1315 of which were excluded from the study because donor gametes were used or the couple was lost to follow-up. Of the 5406 eligible ETs, 2592 (48 \%) were fresh ETs and 2814 (52 \%) were FETs. 503 fresh ETs gave rise to at least one liveborn infant, versus 353 FETs (856 ETs in total). We excluded 94 ETs that resulted in twins (11\%). A further 54 of the remaining 762 ETs were 
Year: 2018

excluded due to missing birthweight data. Our study population thus consisted of 708 singletons (Figure 1).

The characteristics of the women whose embryo transfer resulted in a live singleton birth are shown in Table 1.

In univariate analysis of the 708 singletons studied (Table 1), birthweight was higher in the FET group than in the fresh ET group (3.357.45 g versus $3.183 .22 \mathrm{~g}, \mathrm{p}<0.001)$.

In multivariate analysis, birthweight was adjusted for maternal age, weight, height and parity, and the child's sex and gestational age at birth. The analysis confirmed that birthweight is higher after a pregnancy obtained through FET than through fresh ET. On average, the newborns were $165.2 \mathrm{~g}$ heavier $(95 \% \mathrm{Cl}$ [92.96-237.51] after FET as presented in Table 2. Results are concordant with the study of birthweight adjusted for gestational age.

Furthermore, we found an increased risk of macrosomia in FET compared to fresh ET, OR=2, 52 [1.28-4.94] and $7.5 \%$ of macrosomia in the population.

There was no significant difference between the groups in the women's age or BMI (33.04 years for fresh $\mathrm{ET}$ versus 32.71 years for $\mathrm{FET}, \mathrm{p}=0.43, \mathrm{BMI} p=0.86$ ), gestation length ( 39.18 weeks after fresh $E T, 39.30$ weeks after FET, $p=0.13$ ), or the proportion of preterm births ( $6 \%$ [ 26 cases] after fresh $E T$ versus $8 \%[20]$ after $F E T, p=0.51$ ).

There were more previously nulliparous women in the FET group: 72\% (211) versus 54\% (222), $p<0.001$. There were more induced and caesarean deliveries in the FET group: $29 \%(73)$ and $22 \%(54)$ respectively, versus $21 \%(81)$ and $16 \%$ ( 60 in the fresh ET group, $p=0.03$. The ratio of boys to girls was the same in both groups.

There was no significant difference between the groups in the type or duration of infertility, ART type (IVF versus IVF-ICSI), the stimulation protocol used, embryonic stage at transfer, or the number of embryos transferred. Endometrial thickness was greater in the fresh ET group (10.15 mm versus $8.64 \mathrm{~mm}, \mathrm{p}<.0001)$.

The characteristics of the women who underwent embryo transfer, excluding those who used donor gametes or were lost to follow-up, are shown in Table 4.

Univariate analysis of all the ETs (Table 3 ) showed that a higher proportion of fresh ETs resulted in live birth: $19.37 \%$ (503) versus $12.12 \%$ (353) with FET, $\mathrm{p}<0.001$.

Compared with ETs that failed, more of the ETs that resulted in a live birth were double ETs $(42.70 \%$ [360] versus $36.97 \%$ [1687], $p=0.0025$ ), and in women who had a received an agonist protocol (23.96\% [202] versus 20.27\% [924], $p=0.016)$.

Women who underwent fresh ET were older than those who underwent FET (33.92 years \pm 4.48 versus 33.43 years $\pm 4.32, p<0.001)$ and their endometrial thickness was greater $(9.96 \mathrm{~mm} \pm 2.39$ versus $8.56 \mathrm{~mm} \pm 1.64, p<0.001)$. Women who underwent FET were also more likely to have received an antagonist protocol: $81.49 \%$ (2293), versus $76.59 \%(1983)$ in the fresh ET group, $p<0.001)$. Single 
embryo transfer was more common with FET than with fresh ET: $64.36 \%$ of FETs (1811) versus 53.51\% of fresh ETs (1387), $p<0.001$.

No significant differences in IVF attempt number, ART type (IVF versus IVF-ICSI), embryonic stage at transfer, and smoking status were found between the live birth group and the no live birth group.

Failure to achieve live birth was modelled by multivariate analysis (Table 5).

We obtained more failures to achieve live birth with FET (OR 1.616, 95\% $\mathrm{Cl}$ [1.377-1.896]). The risk of failure increased with each additional year of age (as a continuous variable): OR 1.048, 95\% $\mathrm{Cl}$ [1.031.066]. The risk of failure decreased with each 1-mm increase in endometrial thickness: OR 0.955, $95 \% \mathrm{Cl}[0.923-0.988]$. Fewer failures were obtained with double ET than with single ET (OR 0.823 $95 \% \mathrm{Cl}[0.703-0.962])$, and with an agonist protocol versus an antagonist protocol (OR $0.822,95 \% \mathrm{Cl}$ [0.68-0.98]).

\section{Discussion}

After adjustment for known confounding factors, birthweight was higher after FET than after fresh in univariate and multivariate analysis. This did not appear to be a result of differences in gestation length, as there results are concordant with the study of birthweight adjusted for gestational age.

Our finding is consistent with the literature $(15,20)$, and in particular with Schwarze (14), Korosec (7), and Wennerholm (16). According to A. Pingborg, we found an increased risk of macrosomia in FET compared to fresh ET (21). Reassuringly, the mean birthweight in our study ( $3255 \mathrm{~g}$ ) is close to the national average in France of $3254 \mathrm{~g}(22)$.

The reasons for higher birthweight after FET are unknown. It has been suggested that ET on the second or third day after fertilization in a fresh IVF cycle results in asynchrony between embryonic development and endometrial receptivity, due to the excessive estradiol levels that occur with ovarian stimulation. Conversely, in FET, the uterine environment is more natural and favourable to early placentation and embryogenesis (25). Ovarian stimulation cycles may also impair endometrial angiogenesis.

We used hormone therapy for FET cycles, rather than relying on natural cycles. The hormones were given at physiological doses to mimic a natural cycle, unlike the supraphysiological doses of gonadotrophins used to optimize oocyte retrieval.

Embryo implantation is an important determinant of the success or failure of ART. It depends on three main parameters: embryo quality, endometrial receptivity, and embryo-endometrium interactions. The window of implantation corresponds to the time when the endometrium has acquired the morphology necessary for embryo implantation. In spontaneous conception, this occurs 7 to 10 days after ovulation.

Endometrial receptivity is essential in both natural conception and ART. But ovarian stimulation causes premature endometrial maturation by accelerating these morphological and biochemical 
changes with supraphysiological estradiol $(14,24)$. It has been suggested that ovarian stimulation alters the expression of endometrial genes and estradiol and progesterone receptors $(14,26)$.

ART procedures may also have epigenetic effects and influence birthweight. I.e. reversible changes transmitted to daughter cells that modify gene expression. The mechanism is unknown and most of the data currently available are from animal studies (16).

Murine studies have shown that cultured embryos exhibit variable loss of the genomic imprinting found in naturally derived embryos. These effects may also occur, or may even be more pronounced, in embryos that were previously frozen and thawed. Some authors claim that all ART procedures, from ovulation induction to embryo vitrification, disrupt genomic imprinting (27).

Some randomized studies have shown that the embryo culture medium used in IVF affects birthweight without altering gestation length $(28,29)$. Could this have been due to fetal or placental epigenetic changes, perhaps DNA methylation? All culture media contain growth factors, anti-oxidants, cytokines and vitamins with unknown effects on the embryo. However, culture media vary in composition and other studies have shown no association between the culture medium used and birthweight $(2,30)$, while confirming higher birthweights after FET than after fresh ET. A possible interaction with cryoprotectants has been hypothesized. Studies have also shown that extended culture, in order to transfer blastocysts rather than D3 embryos, increases the risk of macrosomia $(14,29)$. As only $10 \%$ of embryos in our study were blastocysts, we cannot draw any conclusions on this matter.

In our study, the live birth rate for non-donor IVF was higher with fresh ET than with FET, a phenomenon that is much debated in the literature $(13,23,24)$. In most studies, as in ours, the embryos considered to have the greatest implantation potential are transferred first and are therefore fresh. This tends to introduce bias in comparisons of pregnancy rates and live birth rates achieved through FET versus fresh ET. However, in studies that eliminated this bias, the pregnancy rate was higher after FET than after fresh ET (23). Nevertheless, these studies were heterogeneous, with disparate sample sizes, and the embryos were transferred at the blastocyst stage, which accounted for a minority of ETs in our study.

Our caesarean section rate was higher after FET (22\%, versus $16 \%$ after fresh ET), for a national rate of $21 \%(22)$. This is consistent with Maheshwari et al., although the reason for this phenomenon remains unknown (3). In contrast, Pereira found no difference in caesarean section rates (31).

We noticed more nulliparity in FET, maybe a first response for the higher caesarean rate in FET. Nulliparous younger than multiparous ( 33.92 ans \pm 4.48 versus $33.43 \pm 4.32, p<0.001$ ), and younger they are, higher the ovarian reserve is, more ETs are achieved, therefore more FETs.

In our study, antagonist protocol are associated to lower chances of LB than agonist (OR failure to live birth antagonist vs agonist 0.822 (IC 0.687-0.984)) and there were more antagonist protocol during COS before FET (81.49\% (2293), versus $76.59 \%$ in fresh ETs (1983), $p<0.001$ ). Freeze all strategy more often performed after an antagonist protocol and FETs have a lower LBR than fresh ETs which can explain this difference.

In agreement with our results, a study published in 2015 (14) on 43070 fresh ETs and 12068 FETs reported similar preterm delivery rates and gestational ages at birth after FET versus fresh ET. Our preterm birth rate of $6.9 \%$ is close to the national average of $6.6 \%$ for all live births (22). 
One strength of our study is its large sample size (5406 ETs and 856 live births) compared with others in the literature. Its limitations are the fact that it was retrospective and conducted in a single centre, different operators performed ET, some data were missing, and some patients were lost to followup. In particular, the absence of data on the smoking status of patients who underwent FET means that we could not adjust for this factor when interpreting our birthweight data.

In conclusion, the data from this study confirm that birthweight is higher after FET than after fresh $E T$, and provide reassurance over the preterm birth rates associated with fresh ET and FET. However, there is a pressing need for research into the reasons for this birthweight difference. This study is an insufficient basis for advocating a freeze-all strategy, and further research is required to inform this decision. 


\section{REFERENCES}

1. Kansal Kalra S, Ratcliffe SJ, Milman L, Gracia CR, Coutifaris C, Barnhart KT. Perinatal morbidity after in vitro fertilization is lower with frozen embryo transfer. Fertil Steril. 2011 Feb;95(2):548-53.

2. Vergouw CG, Kostelijk EH, Doejaaren E, Hompes PG, Lambalk CB, Schats R. The influence of the type of embryo culture medium on neonatal birthweight after single embryo transfer in IVF. Hum Reprod. 2012 Sep;27(9):2619-26.

3. Maheshwari A, Pandey S, Shetty A, Hamilton M, Bhattacharya S. Obstetric and perinatal outcomes in singleton pregnancies resulting from the transfer of frozen thawed versus fresh embryos generated through in vitro fertilization treatment: a systematic review and meta-analysis. Fertil Steril. 2012 Aug;98(2):368-77 e1-9.

4. Jaques AM, Amor DJ, Baker HW, Healy DL, Ukoumunne OC, Breheny S, et al. Adverse obstetric and perinatal outcomes in subfertile women conceiving without assisted reproductive technologies. Fertil Steril. 2010 Dec;94(7):2674-9.

5. Henningsen AK, Pinborg A, Lidegaard O, Vestergaard C, Forman JL, Andersen AN. Perinatal outcome of singleton siblings born after assisted reproductive technology and spontaneous conception: Danish national sibling-cohort study. Fertil Steril. 2011 Mar 1;95(3):959-63.

6. Zhao J, Xu B, Zhang Q, Li YP. Which one has a better obstetric and perinatal outcome in singleton pregnancy, IVF/ICSI or FET?: a systematic review and meta-analysis. Reprod Biol Endocrinol. 2016 Aug 30;14(1):51.

7. Korosec S, Ban Frangez H, Verdenik I, Kladnik U, Kotar V, Virant-Klun I, et al. Singleton pregnancy outcomes after in vitro fertilization with fresh or frozen-thawed embryo transfer and incidence of placenta praevia. Biomed Res Int. 2014;2014:431797.

8. Sazonova A, Kallen K, Thurin-Kjellberg A, Wennerholm UB, Bergh C. Neonatal and maternal outcomes comparing women undergoing two in vitro fertilization (IVF) singleton pregnancies and women undergoing one IVF twin pregnancy. Fertil Steril. 2013 Mar 1;99(3):731-7.

9. Kallen B, Finnstrom O, Lindam A, Nilsson E, Nygren KG, Otterblad Olausson P. Trends in delivery and neonatal outcome after in vitro fertilization in Sweden: data for 25 years. Hum Reprod. 2010 Apr;25(4):1026-34.

10. Grady R, Alavi N, Vale R, Khandwala M, McDonald SD. Elective single embryo transfer and perinatal outcomes: a systematic review and meta-analysis. Fertil Steril. 2012 Feb;97(2):324-31.

11. Barrière A. Facteurs prédictifs de naissance vivante après transfert d'embryon vitrifié au stade blastocyste. Nantes. 2016.

12. Wennerholm UB, Soderstrom-Anttila V, Bergh C, Aittomaki K, Hazekamp J, Nygren KG, et al. Children born after cryopreservation of embryos or oocytes: a systematic review of outcome data. Hum Reprod. 2009 Sep;24(9):2158-72.

13. Biomédecine Adl. Rapport médical et scientifique de l'assistance médicale à la procréation et de la génétique humaines en France. 2017.2017

14. Schwarze JE, Crosby JA, Zegers-Hochschild F. Effect of embryo freezing on perinatal outcome after assisted reproduction techniques: lessons from the Latin American Registry of Assisted Reproduction. Reprod Biomed Online. 2015 Jul;31(1):39-43.

15. Pelkonen S, Koivunen R, Gissler M, Nuojua-Huttunen S, Suikkari AM, Hyden-Granskog C, et al. Perinatal outcome of children born after frozen and fresh embryo transfer: the Finnish cohort study 1995-2006. Hum Reprod. 2010 Apr;25(4):914-23.

16. Wennerholm UB, Henningsen AK, Romundstad LB, Bergh C, Pinborg A, Skjaerven R, et al. Perinatal outcomes of children born after frozen-thawed embryo transfer: a Nordic cohort study from the CoNARTaS group. Hum Reprod. 2013 Sep;28(9):2545-53.

17. Davies MJ, Moore VM, Willson KJ, Van Essen P, Priest K, Scott H, et al. Reproductive technologies and the risk of birth defects. N Engl J Med. 2012 May 10;366(19):1803-13.

18. Custers IM, Konig TE, Broekmans FJ, Hompes PG, Kaaijk E, Oosterhuis J, et al. Couples with unexplained subfertility and unfavorable prognosis: a randomized pilot trial comparing the 
effectiveness of in vitro fertilization with elective single embryo transfer versus intrauterine insemination with controlled ovarian stimulation. Fertil Steril. 2011 Nov;96(5):1107-11 e1.

19. Ego A, Prunet C, Lebreton E, Blondel B, Kaminski M, Goffinet F, et al. [Customized and noncustomized French intrauterine growth curves. I - Methodology]. J Gynecol Obstet Biol Reprod (Paris). 2016 Feb;45(2):155-64.

20. Vidal M, Vellve K, Gonzalez-Comadran M, Robles A, Prat M, Torne M, et al. Perinatal outcomes in children born after fresh or frozen embryo transfer: a Catalan cohort study based on 14,262 newborns. Fertil Steril. 2017 Apr;107(4):940-7.

21. Berntsen S, Pinborg A. Large for gestational age and macrosomia in singletons born after frozen/thawed embryo transfer (FET) in assisted reproductive technology (ART). Birth Defects Res. 2018 May 1;110(8):630-43.

22. Blondel. Les naissances en 2010 et leur évolution depuis 2003. Unité de Recherche Épidémiologique en Santé Périnatale et Santé des Femmes et des Enfants, INSERM - U 953 2011; Enquête nationale périnatale 2010

23. Roque M, Lattes K, Serra S, Sola I, Geber S, Carreras R, et al. Fresh embryo transfer versus frozen embryo transfer in in vitro fertilization cycles: a systematic review and meta-analysis. Fertil Steril. 2013 Jan;99(1):156-62.

24. Roque M, Valle M, Guimaraes F, Sampaio M, Geber S. Freeze-all policy: fresh vs. frozenthawed embryo transfer. Fertil Steril. 2015 May;103(5):1190-3.

25. Maheshwari A, Raja EA, Bhattacharya S. Obstetric and perinatal outcomes after either fresh or thawed frozen embryo transfer: an analysis of 112,432 singleton pregnancies recorded in the Human Fertilisation and Embryology Authority anonymized dataset. Fertil Steril. 2016 Dec;106(7):1703-8.

26. Celik S, Turgut NE, Yagmur E, Boynukalin K, Celik DC, Findikli N, et al. The effects of fresh embryo transfers and elective frozen/thawed embryo transfers on pregancy outcomes in poor ovarian responders as defined by the Bologna criteria. Turk J Obstet Gynecol. 2015 Sep;12(3):132-8. 27. Market Velker BA, Denomme MM, Mann MR. Loss of genomic imprinting in mouse embryos with fast rates of preimplantation development in culture. Biol Reprod. 2012 May;86(5):143, 1-16. 28. Kleijkers SH, Mantikou E, Slappendel E, Consten D, van Echten-Arends J, Wetzels AM, et al. Reply II: Embryo culture media effects. Hum Reprod. 2017 Mar 1;32(3):717-8.

29. Zhu J, Lin S, Li M, Chen L, Lian Y, Liu P, et al. Effect of in vitro culture period on birthweight of singleton newborns. Hum Reprod. 2014 Mar;29(3):448-54.

30. Lin S, Li M, Lian Y, Chen L, Liu P. No effect of embryo culture media on birthweight and length of newborns. Hum Reprod. 2013 Jul;28(7):1762-7.

31. Pereira N, Petrini AC, Lekovich JP, Schattman GL, Rosenwaks Z. Comparison of perinatal outcomes following fresh and frozen-thawed blastocyst transfer. Int J Gynaecol Obstet. 2016 Oct;135(1):96-100. 
Year: 2018

\section{Figure 1: Flowchart}

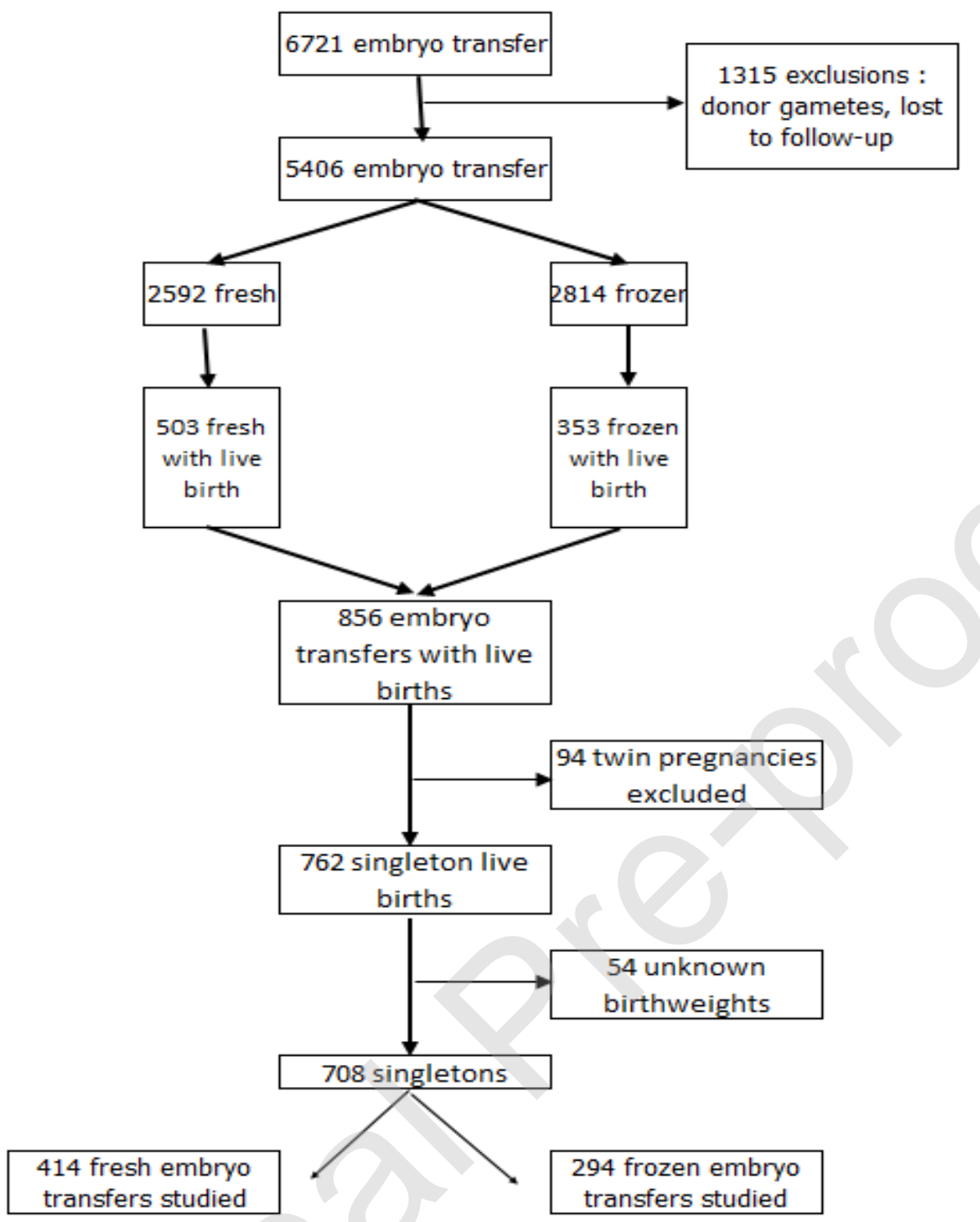


Table 1: Description of the population of the embryo transfers that resulted in a live singleton birth

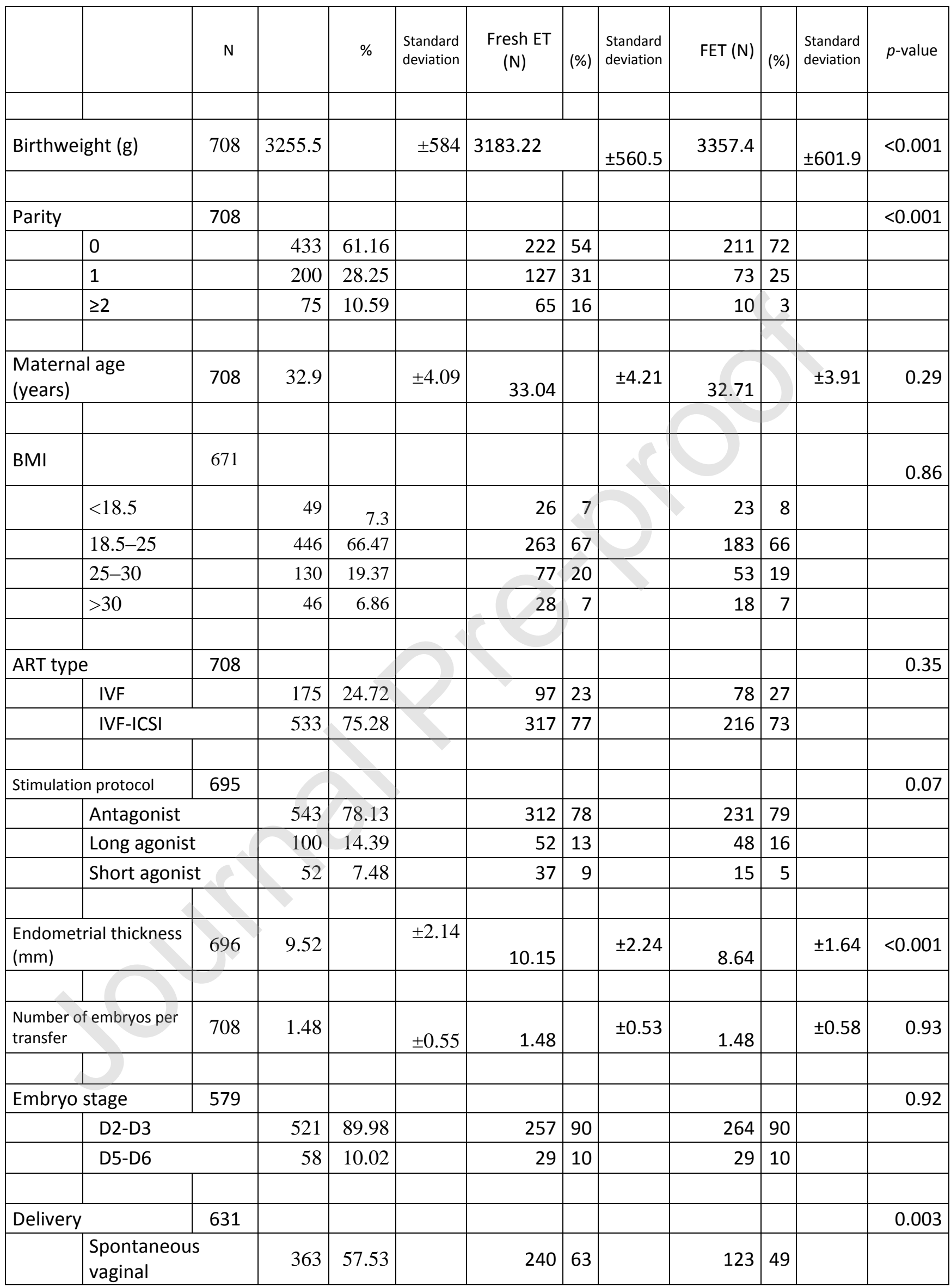




\begin{tabular}{|c|c|c|c|c|c|c|c|c|c|c|c|c|}
\hline & \multicolumn{2}{|c|}{ Induced vaginal } & 154 & 24.41 & & 81 & 21 & & 73 & 29 & & \\
\hline & \multicolumn{2}{|c|}{ Caesarean } & 114 & 18.07 & & 60 & 16 & & 54 & 22 & & \\
\hline \multicolumn{2}{|c|}{ Gestation (weeks) } & 658 & 39.22 & & \pm 1.93 & 39.18 & & \pm 1.90 & 39.30 & & \pm 1.98 & 0.13 \\
\hline \multicolumn{2}{|l|}{ Preterm } & 658 & & & & & & & & & & 0.51 \\
\hline & Yes & & 46 & 6.99 & & 26 & 6 & & 20 & 8 & & \\
\hline & No & & 612 & 93.01 & & 376 & 94 & & 236 & 92 & & \\
\hline \multicolumn{2}{|l|}{ Child'sex } & 703 & & & & & & & & & & 0.08 \\
\hline & Girl & & 361 & 51.35 & & 224 & 54 & & 137 & 47 & & \\
\hline & Boy & & 342 & 48.65 & & 190 & 46 & & 152 & 53 & & \\
\hline
\end{tabular}

Table 2: Association between birthweight and ET type

\begin{tabular}{|c|c|c|c|c|}
\hline & & \multicolumn{3}{|c|}{ Birthweight } \\
\hline & & Beta adjusted $^{a}$ & IC $95 \%$ & $p$ value \\
\hline \multirow[t]{4}{*}{ Embryo transfert type } & Fresh ET & Ref & 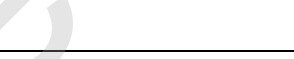 & \\
\hline & FET & 165.23 & {$[92.96 ; 237.51]$} & $<0.0001$ \\
\hline & & \multicolumn{3}{|c|}{ Z score Birthweight } \\
\hline & & Beta adjusted $^{\mathrm{b}}$ & IC $95 \%$ & $p$ value \\
\hline \multirow[t]{2}{*}{ Embryo transfert type } & Fresh ET & Ref & & \\
\hline & FET & 0.36 & {$[0.20 ; 0.52]$} & $<0.0001$ \\
\hline
\end{tabular}

a adjusted for mother's weight before the pregnancy, mother's height, height squared, parity, gestational age at birth, gestation squared, gestation cubed, and the baby's sex

a adjusted for mother's weight before the pregnancy, mother's height, height squared, parity, and the baby's sex 
Year: 2018

Table 3 : Macrosomia and ET type

\begin{tabular}{|c|c|c|c|}
\hline \multicolumn{4}{|c|}{ macrosomia } \\
\hline \multirow{2}{*}{ macrosomia } & \multicolumn{3}{|c|}{ Transfert_E(Transfert_E) } \\
\hline & fresh ET & FET & Total \\
\hline \multirow{4}{*}{0} & 389 & 262 & 651 \\
\hline & 55.26 & 37.22 & 92.47 \\
\hline & 59.75 & 40.25 & \\
\hline & 94.88 & 89.12 & \\
\hline \multirow{4}{*}{1} & 21 & 32 & 53 \\
\hline & 2.98 & 4.55 & 7.53 \\
\hline & 39.62 & 60.38 & \\
\hline & 5.12 & 10.88 & \\
\hline \multirow{2}{*}{ Total } & 410 & 294 & 704 \\
\hline & 58.24 & 41.76 & 100.00 \\
\hline
\end{tabular}


Table 4: Characteristics of the population that underwent embryo transfer

\begin{tabular}{|c|c|c|c|c|c|c|c|c|c|c|c|c|}
\hline & & $\mathrm{N}$ & & $\%$ & $\begin{array}{l}\text { Standard } \\
\text { deviation }\end{array}$ & $\begin{array}{l}\text { Fresh } \\
\text { ET (N) }\end{array}$ & $\%$ & $\begin{array}{l}\text { Standard } \\
\text { deviation }\end{array}$ & $\begin{array}{l}\text { FET } \\
(N)\end{array}$ & $\%$ & $\begin{array}{l}\text { Standard } \\
\text { deviation }\end{array}$ & $\begin{array}{c}p- \\
\text { value }\end{array}$ \\
\hline \multicolumn{2}{|c|}{ Outcome of transfer } & 5406 & & & & & & & & & & \\
\hline & \multicolumn{2}{|c|}{ Live birth } & 856 & 15.59 & & 503 & 19.37 & & 353 & 12.12 & & $<0.001$ \\
\hline & \multicolumn{2}{|c|}{ Pregnancy loss } & 946 & 17.74 & & 539 & 21.06 & & 407 & 14.68 & & \\
\hline & \multicolumn{2}{|c|}{ No pregnancy } & 3604 & 66.67 & & 1550 & 59.57 & & 2054 & 73.21 & & \\
\hline \multicolumn{2}{|c|}{ Maternal age (years) } & 5406 & 33.67 & & \pm 4.40 & 33.92 & & \pm 4.48 & 33.43 & 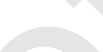 & \pm 4.32 & $<0.001$ \\
\hline \multicolumn{2}{|c|}{$\begin{array}{l}\text { Endometrial } \\
\text { thickness }(\mathrm{mm})\end{array}$} & 5353 & 9.23 & & \pm 2.15 & 9.96 & & \pm 2.39 & 8.56 & & \pm 1.64 & $<0.001$ \\
\hline \multicolumn{2}{|l|}{ ART type } & 5406 & & & & & & & $\theta$ & & & \\
\hline & IVF & & 1488 & 27.52 & & 686 & 26.47 & & 802 & 28.5 & & 0.0998 \\
\hline & \multicolumn{2}{|l|}{ IVF-ICSI } & 3918 & 72.48 & & 1906 & 73.53 & 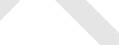 & 2012 & 71.5 & & \\
\hline \multicolumn{2}{|l|}{$\begin{array}{l}\text { Stimulation } \\
\text { protocol }\end{array}$} & 5402 & & & & & ( & & & & & \\
\hline & \multicolumn{2}{|c|}{ Antagonist } & 4276 & 79.14 & & 1983 & 76.59 & & 2293 & 81.49 & & $<0.001$ \\
\hline & \multicolumn{2}{|c|}{ Long agonist } & 760 & 14.07 & & 346 & 13.36 & & 414 & 14.71 & & \\
\hline & \multicolumn{2}{|c|}{ Short agonist } & 366 & 6.77 & $\theta$ & 260 & 10.04 & & 106 & 3.77 & & \\
\hline \multicolumn{2}{|c|}{$\begin{array}{l}\text { Number of embryos } \\
\text { transferred }\end{array}$} & 5385 & 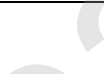 & 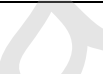 & & & & & & & & \\
\hline & 1 & & 3198 & 59.16 & & 1387 & 53.51 & & 1811 & 64.36 & & $<0.001$ \\
\hline & 2 & A & 2047 & 37.87 & & 1145 & 44.17 & & 902 & 32.05 & & \\
\hline & 3 & & 140 & 2.59 & & 60 & 2.31 & & 101 & 3.59 & & \\
\hline & 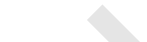 & 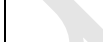 & & & & & & & & & & \\
\hline & & 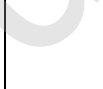 & & & & \multicolumn{2}{|c|}{$\begin{array}{l}\text { Live birth } \\
\text { (\%) }\end{array}$} & & \multicolumn{2}{|c|}{$\begin{array}{c}\text { No live birth } \\
\text { (\%) }\end{array}$} & & \\
\hline \multicolumn{2}{|c|}{ Stimulation protocol } & 5402 & & & & & & & & & & \\
\hline A & \multicolumn{2}{|c|}{ Antagonist } & 4276 & 79.14 & & 641 & 76.04 & & 3635 & 79.73 & & 0.016 \\
\hline & \multicolumn{2}{|l|}{ Agonist } & 1126 & 20,84 & & 202 & 23.96 & & 924 & 20.27 & & \\
\hline \multicolumn{2}{|c|}{$\begin{array}{l}\text { Number of embryos } \\
\text { transferred }\end{array}$} & 5385 & & & & & & & & & & \\
\hline & 1 & & 3198 & 59.16 & & 466 & 55.28 & & 2732 & 59.87 & & 0.0025 \\
\hline & 2 & & 2047 & 37.87 & & 360 & 42.70 & & 1687 & 36.97 & & \\
\hline
\end{tabular}




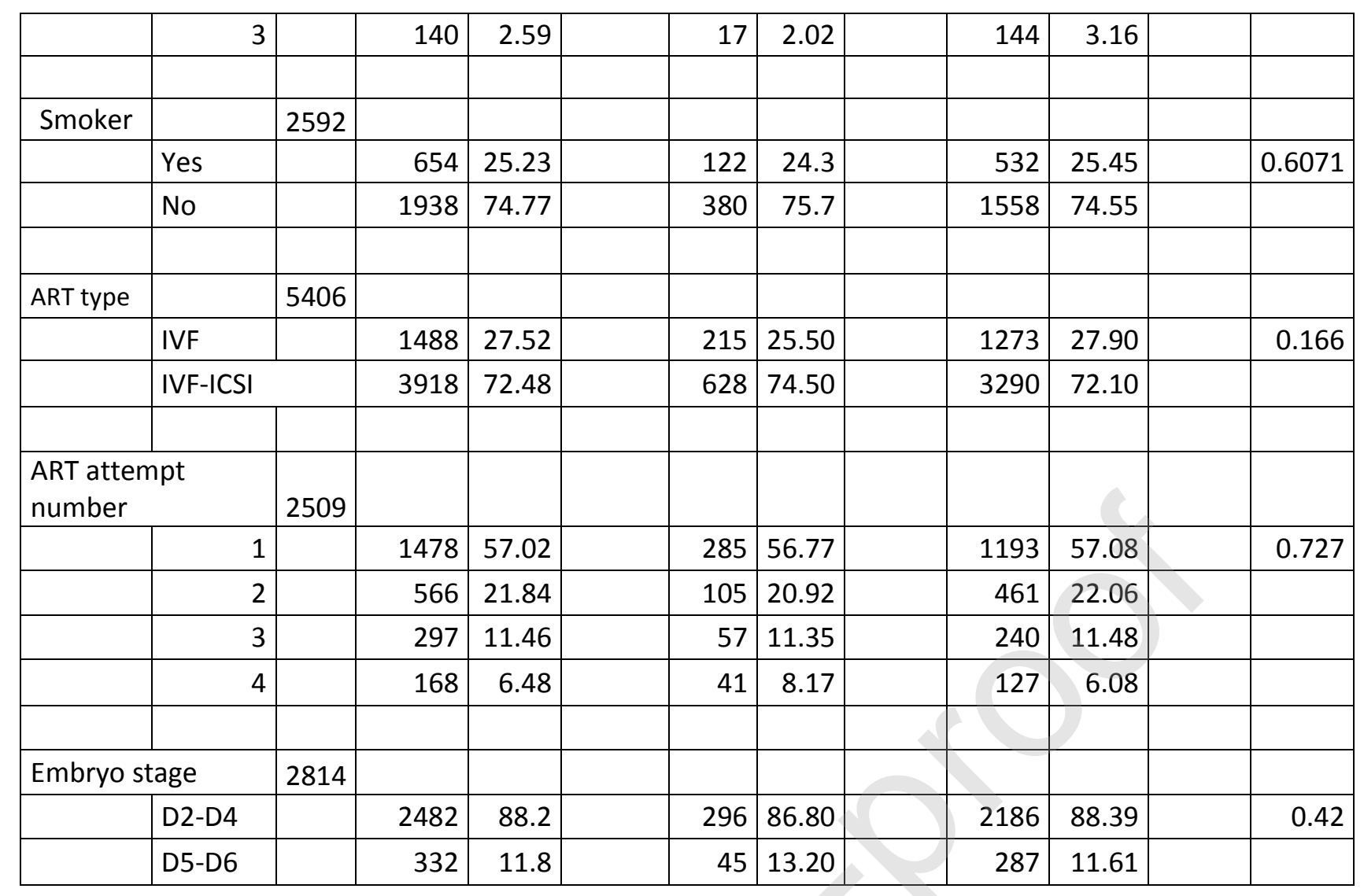

Table 5: Multivariate analysis to model failure to achieve a live birth

\begin{tabular}{|l|l|c|r|}
\hline & & OR & $95 \%$ confidence interval \\
\hline Embryo transfer type & FET vs fresh ET & 1.616 & $1.377-1.896$ \\
\hline Age increase (continuous) & per year & 1.048 & $1.03-1.066$ \\
\hline Increase in endometrial thickness & per mm & 0.955 & $0.923-0.988$ \\
\hline No. of embryos transferred & 2 vs 1 & 0.823 & $0.703-0.962$ \\
\hline No. of embryos transferred & 3 vs 1 & 1.285 & $0.766-2.156$ \\
\hline Stimulation protocol & agonist vs antagonist & 0.822 & $0.687-0.984$ \\
\hline
\end{tabular}

